\title{
High behavioural variability mediated by altered neuronal excitability in auts2
}

\section{mutant zebrafish}

Urvashi Jha ${ }^{1,2,5}$, Igor Kondrychyn ${ }^{1,5,6}$, Vladimir Korzh ${ }^{3,4,7}$, Vatsala Thirumalai ${ }^{1^{*}}$

${ }^{1}$ National Centre for Biological Sciences, Tata Institute of Fundamental Research,

Bellary Road, Bangalore 560065 India.

${ }^{2}$ SASTRA Deemed University, School of Chemical and Biotechnology, Thanjavur, 613401 India.

${ }^{3}$ Institute of Molecular and Cell Biology, 8-13, 61 Biopolis Dr., Proteos, 138673, Singapore.

${ }^{4}$ International Institute of Molecular and Cell Biology, 4 Ks. Trojdena Street, 02-109 Warsaw, Poland.

\section{${ }^{5}$ These authors contributed equally.}

${ }^{6}$ Current address: RIKEN Center for Biosystems Dynamics Research, 2-2-3 Minatojima-minamimachi, Kobe 650-0047, Japan.

${ }^{7}$ Current address: International Institute of Molecular and Cell Biology, $4 \mathrm{Ks}$. Trojdena Street, 02-109 Warsaw, Poland.

*Correspondence: vatsala@ncbs.res.in

Number of pages: 40; Figures: 6; Supplementary figures: 2

Number of words: 8559; Abstract: 211; Introduction: 732; Discussion: 1226

Keywords: escape behavior, C-start, Mauthner, transcription, calcium imaging, intrinsic properties.

Acknowledgements: The authors would like to thank the following sources of funding support: Wellcome Trust-DBT India Alliance Intermediate and Senior fellowships (VT), Department of Biotechnology (VT), Science and Engineering Research Board, Department 
of Science and Technology (VT), Department of Atomic Energy (VT-12-R\&D-TFR-5.04-

0800), CSIR-UGC fellowship (UJ), NCBS Career Development Fellowship (IK). VK's

laboratory in the IMCB, Singapore was supported by the institutional grant to the IMCB by

the Agency for Science, Technology and Research of Singapore. VK in Poland was

supported by the Opus grant of the National Science Foundation (NCN), Poland

(2016/21/B/NZ3/00354).

The authors would also like to thank T.P. Jagadeesh for maintaining the fish facility.

\section{Significance statement:}

AUTS2 is one among recently identified autism susceptibility candidate genes, whose function in neuronal circuits is unclear. Using zebrafish as a model organism, we probe the function of Auts2a (homolog of mammalian AUTS2) at the cellular, network and behavioral levels. The escape behavior of Auts2a mutant zebrafish is highly variable with normal short latency escapes, long latency escapes and total failures across trials in the same fish. This occurs because neuronal excitability is inappropriately set in the Mauthner neurons of mutants leading to the large trial-totrial variability in responses. The behavioral variability is fully explained by variability in firing action potentials in the Mauthner neuron, providing an integrative understanding of how behavioral variability arises from mutations at the genetic level. 


\section{Abstract}

Autism spectrum disorders (ASDs) are characterized by abnormal behavioral traits arising from neural circuit dysfunction. While a number of genes have been implicated in ASDs, in most cases, a clear understanding of how mutations in these genes lead to circuit dysfunction and behavioral abnormality is absent. The autism susceptibility candidate 2 (AUTS2) gene is one such gene, associated with ASDs, intellectual disability and a range of other neurodevelopmental conditions. Yet, the function of AUTS2 in neural development and circuit function is not at all known. Here, we undertook functional analysis of Auts2a, the main homolog of AUTS2 in zebrafish, in the context of the escape behavior. Escape behavior in wild type zebrafish is critical for survival and is therefore, reliable, rapid, and has well-defined kinematic properties. Auts $2 a^{-/}$zebrafish are viable, have normal gross morphology and can generate escape behavior with normal kinematics. However, the behavior is unreliable and delayed, with high trial-to-trial variability in the latency. We demonstrate that this is due to the reduced excitability of Mauthner neurons resulting in unreliable firing with stimuli that normally elicit the escape response. Combined with previous studies that show Auts2-regulation of the transcription of ion channel proteins, our results suggest that Auts 2 sets the excitability of neurons by activating a set transcriptional program. 


\section{Introduction}

Every neuron needs to carefully tune its excitability to be able to perform computation within the circuit in which it is embedded. When firing properties are improperly specified, neuronal function is compromised leading to abnormal behaviors. Transcriptional regulation plays important roles in specifying neuronal excitability properties and therefore, are also a chief class of genes implicated in neurological diseases such as Autism spectrum disorders (ASDs; (Bourgeron, 2015; De Rubeis et al., 2014; Sztainberg and Zoghbi, 2016)). The autism susceptibility candidate 2 (AUTS2, also known as activator of transcription and developmental regulator) gene is a known regulator of transcription in the nervous system (Gao et al., 2014; Russo et al., 2018; Wang et al., 2018) and is associated with several neurodevelopmental disorders including ASD (Beunders et al., 2013; Kalscheuer et al., 2007; Sultana et al., 2002). AUTS2 is expressed in neurons of the central nervous system and is present both in the nucleus and in the cytoplasm (Bedogni et al., 2010; Gao et al., 2014; Hori et al., 2014; Hori and Hoshino, 2017). In the nucleus, AUTS2 binds to members of the Polycomb Repressor Complex 1 (PRC1), but activates transcription of several genes important for neural development and function (Gao et al., 2014; Oksenberg et al., 2014; Wang et al., 2018). In the cytoplasm, AUTS2 regulates actin cytoskeleton to control neuronal migration and neurite outgrowth (Hori et al., 2014; Hori and Hoshino, 2017). Auts2 knockout-mice exhibited several deficits such as reduced righting reflexes and ultrasonic vocalizations (Gao et al., 2014). Nevertheless, how AUTS2 controls nervous system development, function and behavioral output are not understood at all.

We identified and characterized four paralogs of auts2 in zebrafish: auts2a, auts2b, fibrosin-like 1(fbrs/1) and fibrosin (fbrs) (Kondrychyn et al., 2017). Both 
auts $2 a$ and auts $2 b$ genes are expressed in the developing and juvenile zebrafish brain. Analysis of gene structure and protein sequence revealed that among the two genes, auts $2 a$ is the closest orthologue to mammalian Auts2 $(61.58 \%$ identity in protein sequence), with even higher homology in the C-terminus, hinting at conserved binding partners and function. In larval zebrafish, auts2a is widely expressed in the brain with distinctly high expression in rhombomere 4 (Kondrychyn et al., 2017), which houses neurons of the escape network (Metcalfe et al., 1986).

Teleost escape behavior consists of a sharp C-shaped tail bend away from the inducing stimulus with only a few milliseconds latency (Kimmel et al., 1974; Eaton et al., 1977). The behavior is triggered by action potential firing in one of two bilaterally located giant Mauthner neurons (M-cells) (Eaton and Farley, 1975; Eaton et al., 1977; Korn and Faber, 2005; Kohashi and Oda, 2008; Sillar, 2009). Two pairs of homologous neurons, MiD2cm and MiD3cm, also take part in escape behaviors but fire at much longer latencies (Eaton et al., 1984; Kohashi and Oda, 2008).

Action potential firing in M-cells is required for the fast C-start response (Zottoli, 1977; Eaton et al., 1981). In response to supra-threshold depolarization via strong synaptic inputs or by direct current injection, M-cells in larval and adult zebrafish, as well as adult gold fish, generate a single action potential with a very short latency (Eaton et al., 2001; Nakayama and Oda, 2004; Watanabe et al., 2013). This action potential is conducted quickly via its giant axons to spinal circuitry, including direct synapses onto contralateral motor neurons, resulting in rapid muscle contraction and a sharp bending of the body (Fetcho, 1991). M-cell excitability is thus critical for quick escape from threatening stimuli. Though not all of the conductances driving Mcell response have been delineated, it is clear that during development, M-cell intrinsic properties are progressively tuned to result in its mature firing behavior 
(Brewster and Ali, 2013; Watanabe et al., 2017, 2013). Since auts2a is expressed in rhombomere 4 at stages when M-cell properties are being defined, we sought to determine how Auts2a impacts excitability of M-cells and therefore the escape behavior itself.

Using customized transcription activator-like effector nucleases (TALENs), we generated mutations in the auts2a locus and isolated an allele which had a premature stop codon in the coding sequence. Using a combination of high speed videography and in vivo calcium imaging, we show that escape behaviors become highly unreliable and slow in auts $2 a$ mutants and that this unreliability can be explained by the reduced excitability of M-cells. These results indicate a role for Auts $2 a$ in regulating neuronal excitability, an action by which Auts $2 a$ impacts behaviors significantly.

\section{Results}

\section{Generation of the auts2a knockout zebrafish line}

A pair of TALENs were designed to target the donor splice site at exon 8 of the auts2a gene (Figure 1A). The TALEN-targeted sequences surround a restriction enzyme site for easy screening through introduction of a restriction fragment length polymorphism. We identified 5 different mutant alleles, 3 of which led to a frameshift after S498 and premature stop codons after several missense amino acids (Figure 1B) and one of them, auts $2 a^{n c b 104}$, was selected to establish an auts2a KO zebrafish line. This line harbours a 11-nt deletion, which disrupts the donor splice site affecting correct splicing between exon 8 and exon 9. RT-PCR analysis of RNA isolated from homozygotes revealed, that auts $2 a^{n c b 104}$ pre-mRNA uses two alternative cryptic donor splice sites found in intron in order to splice exon 8 to exon 9 (Figure 1A, B). 
As a result, intronic sequence is partially retained in auts $2 a^{n c b 104} \mathrm{mRNA}$ leading to a premature stop codon at amino acid 504 after 6 missense amino acids (Figure 1B).

The zebrafish Auts2a protein has several domains, previously predicted in human AUTS2 (Sultana et al., 2002): two proline-rich (PR) regions, PR1 at amino acids 273-492 and PR2 at amino acids 558-656, PY (PPPY) motif at amino acids 524-528, and the Auts2 family domain at amino acids 660-882 (Figure 1B). In Auts $2 a^{\text {ncb104 }}$, only the PR1 region is retained (Figure 1B). Recently, we described the transcriptional complexity found in the zebrafish auts2a gene locus that is mediated by alternative splicing and alternative promoter usage (Kondrychyn et al., 2017). Exon 8 is a common exon in all isoforms (Supplemental Figure S1A) and in auts2a $a^{\text {ncb104 }}$ mutant all isoforms will be similar affected: a loss of the C-terminal portion of Auts2a, comprising PY motif, PR2 region and the Auts2 family domain (Supplemental Figure S1B).

\section{auts2a mutants display high variability in escape responses}

Auts2a KO zebrafish showed normal development and gross morphology (Supplemental Figure S2A). Moreover, auts2a $a^{\text {ncb104 }}$ homozygote fish survive to become fertile adults. As auts $2 a$ is a neurodevelopmental gene (Oksenberg and Ahituv, 2013) and is expressed at very high levels in rhombomere 4 (Kondrychyn et al., 2017), which houses the escape network, we first investigated whether M-cells, the command-like neurons driving escape behavior, are present in auts2a mutants. Wild type larvae possess a single pair of M-cells that send commissural axons down the spinal cord (Fetcho, 1991). In auts2a mutants both M-cells are present and send commissural axons (Supplemental Figure S2B). However, M-cells in auts2a mutants were smaller: both soma volume and dendritic length were significantly reduced 
(Supplemental Figure S2C-E). This suggests possible effects on M-cell function leading to deficits in escape behavior.

Next, we asked if auts2a mutants exhibited any deficits in escape behavior. We evoked the C-start escape behavior in partially restrained zebrafish larvae between 6-8 days post fertilization (dpf), by directing a strong jet of water at the otic vesicle (OV) (Figure 2A). The restrained preparation ensures similar location of water jet delivery across larvae. The C-start escape response consists of a large angle contralateral tail bend initiated within 3-13 ms of stimulus delivery (Figure 2B). We measured three parameters associated with the C-start escape response: the probability of initiating escapes (\% trials where escapes were observed), the latency (time from stimulus arrival at the OV to movement onset) and the maximum tail bend angle, in wild type, heterozygotes and auts2a mutant larvae. First, auts2a mutants showed a higher percentage of failures to initiate escape responses compared to heterozygotes and wild type larvae (Figure 2C). While wild type and heterozygote larvae showed a contralateral tail bend response in nearly $98 \%$ of trials, auts $2 a$ mutants were able to generate escapes in only $76 \%$ of trials. Mutants also had increased probability of failures (no tail bend response) compared to heterozygote and wild type larvae. Next, we asked if the increased failure rates observed in mutants was due to few individuals that did not respond across any of the trials. Surprisingly, we observed that individual larvae displayed highly variable responses across trials (supplementary video 1). Figure 2D shows responses from 5 wild type and 5 mutant larvae across 6 trials. While all wild type larvae were able to initiate escape responses within $10-20 \mathrm{~ms}, 4$ of 5 auts2a mutants showed failures in at least

one trial. In addition, the latency to initiate escapes were longer and more variable in 
mutants compared to wild type (Range: 3-552 ms; Figure 2D, E). Escape response

can be generated via multiple pathways. While fast escape responses to head directed stimuli result from activation of the M-cells and its segmental homologs (Mseries) (Kohashi and Oda, 2008; Liu and Fetcho, 1999), neural circuitry underlying long-latency escape responses are less well understood (but see (Marquart et al., 2019). Therefore, we next compared latencies of the fast escape response (cut-off latency: $\leq 20 \mathrm{~ms}$ ) between wild type, heterozygotes and auts2a mutants. Fast escape responses in auts2a mutants occur at longer latencies compared to wild type (Figure $2 F)$. Further, the coefficient of variation (CV) of latencies for individual larvae across successive trials was significantly higher for the mutant group in comparison to wild type larvae (Figure 2G). Nevertheless, the kinematics of the escape response were not affected in mutants, as evidenced by the similar maximal tail bend angles observed (Figure $2 \mathrm{H}$ ). Thus, initiation of tightly regulated, high performance escape response is unreliable and slow in auts2a mutants.

\section{Escape response defects in auts2a mutants persist on changing the location of sensory stimulation}

Stimulation of the OV with water jet activates the M-cell and its homologs, while the same stimulus applied to the tail activates the M-cell alone (Liu and Fetcho, 1999). To investigate if M-cell firing is compromised in auts $2 a^{\text {ncb104 }}$ larvae, we applied the water jet to the tail at the level of the cloaca (Figure 3A, B). In wild type larvae, tail stimulation with water pulse resulted in fast escape responses with 
characteristic short latency and contralateral tail bend in $83 \%$ trials (Figure 3B, C). Similar to OV stimulation, auts2a mutants displayed a high percentage of failures in escape response but similar percentage of ipsilateral tail bend responses to wild type (Figure 3C). Tail stimulation also resulted in significantly longer latencies in mutants than in wild type larvae (Figure 3D). However, no significant difference was observed in the coefficient of variation of latencies across trials in an individual larva between wild type and mutants (Figure 3E), implying that the increased variability of latency seen with OV stimulation could result from recruitment of the M-cell homologs. No difference was observed in tail bend angles between wild type and mutant groups (Figure 3F).

\section{Mauthner neuron fails to fire reliably in auts2a mutants}

To directly assess M-cell firing in auts2a mutants, we next monitored calcium activity in OGB-1 dextran labelled M-cells upon electrical stimulation of OV (Figure 4A). OV stimulation resulted in a large increase in fluorescence from rest (Figure 4B, C, supplementary video 2) and this response was evoked reliably in wild type larvae (Figure 4B-D). Mutants displayed greater proportion of failures in calcium response (Figure 4B-D, supplementary video 3). Mutants also showed lower peak calcium signals compared to wild type (Figure 4C, E). In addition, the CV of the peak calcium response was not statistically different between wild type and mutant larvae. This implies that the increased variability in latency seen with OV stimulation (Figure 2F) does not arise from variability in response of the M-cell itself.

\section{Mauthner neurons in auts2a mutants have reduced excitability}


Failures in calcium activity response in the mutants after OV stimulation could result either from reduced excitability of M-cells and/or defects in sensory processing involving mechanosensory hair cells and the VIIIth cranial nerve. To ascertain the role of the M-cells, we stimulated its axon (antidromic stimulation) which resulted in calcium activity transients similar to OV stimulation (Figure 5A).

Due to the large diameter of the M-cell axon, it has the lowest threshold for extracellular stimulation (Kimmel et al., 1982). At low stimulation intensity other cells are unlikely to be activated, making the stimulation M-cell-specific. We defined the threshold intensity as the minimum stimulus intensity at which calcium signals were evoked in the M-cell during all 5 trials (Figure 5B). Compared to wild type, threshold intensity was significantly higher in auts2a mutants (Figure 5C-E). However, at intensities equal to or higher than threshold, M-cells responded reliably in both mutants and wild type larvae (Figure 5F) and the peak calcium signal was significantly reduced in mutants compared to wild type larvae (Figure 5G, H), similar to that seen after OV stimulation (Figure 4E, F). These results show that the increased failures, latency and variability in latencies all derive from increased threshold to fire in M-cells. This in turn is due to decreased excitability of these cells in auts2a mutants.

\section{Discussion}

We show that Auts2a function is essential for setting the excitability of M-cells in the escape circuit. As a consequence of auts2a mutation, reliable firing of M-cells is lost and therefore, escape responses become unreliable also. In trials where neither the M-cell nor its homologs fire, fish fail to generate escape responses, while in trials where only the homologs fire, the latency to respond is longer. Auts2a 
mutant fish exhibit increases in both failures and latencies, indicating deficits in excitability of the M-cell and its homologs (Figure 6). We confirmed the hypoexcitability of the mutant M-cells by directly stimulating the M-axon. Mounting an appropriate and fast escape response reliably is essential for survival and thus Auts2a serves an essential function for the animal. These findings place Auts $2 a$ as an important transcriptional regulator of neuronal intrinsic properties, ultimately setting the function of neuronal circuits. This study thus uncovers a hitherto unknown, but essential function of Auts2 family proteins in neural circuit function and behavior.

\section{The escape circuit as a model circuit for testing gene function}

The escape system in zebrafish has been a fantastic tool for dissecting the genetic underpinnings of behavior, learning and decision-making (Gahtan and Baier, 2004; Wolman and Granato, 2012). Forward genetic screens identified mutants with specific deficits in generating escapes such as the twitch twice and space cadet mutants (Burgess et al., 2009; Granato et al., 1996; Lorent et al., 2001). More recent studies have reported mutants with deficits in sensitivity (Marsden et al., 2018), habituation (Wolman et al., 2015), pre-pulse inhibition (Burgess and Granato, 2007) or in deciding between Mauthner-mediated short latency escapes and non-Mauthner mediated long latency escapes (Jain et al., 2018). The specific defects identified in these studies range from errors in axon guidance, extracellular calcium sensing and IGF signaling in M-cells and other members of the escape circuit. Our study makes an important addition to these studies by identifying Auts2a to be a direct genetic determinant of excitability in M-cells and its homologs. 
M-cells are specified soon after gastrulation and evoke escape responses to touch in larvae as young as early as 2 dpf (Kimmel et al., 1974; Kohashi et al., 2012). As the lanae mature, M-cells drive startle behaviors in response to auditory/vestibular stimulation as well. Concomitant with these changes, the firing behavior of M-cells changes from firing multiple action potentials upon reaching threshold to firing only a single action potential after $4 \mathrm{dpf}$. This change in firing behavior of the M-cells drives maturation of the escape behavior from one involving multiple C-bends to that with only a single C-bend followed by routine swimming. The alteration in M-cell firing behavior is in part due to the expression of distinct types of potassium channels including those that are sensitive to dendrotoxin (Watanabe et al., 2013, 2017). These studies underline the critical importance of regulating the intrinsic properties of M-cells for generating appropriate C-start behaviors. Hyperexcitability will result in multiple C-starts while hypo-excitability in Mcells and its homologs, as seen in auts2a mutants will lead to failures in escapes.

\section{Mechanism of action}

ChIP-seq analysis revealed that in mouse brain, AUTS2 binds preferentially to promoter and enhancer regions of genes involved in nervous system development (Gao et al., 2014; Oksenberg et al., 2014). In mouse forebrain alone, 784 AUTS2 binding sites were in promoter regions and 1146 sites were distal to promoter regions. Regardless of whether the sites were within promoter regions, these AUTS2 binding sites were found to be associated with genes implicated in ASDs. Further, binding of AUTS2 to these sites seems to activate their expression resulting in higher transcript levels. Importantly, among the targets of AUTS2 binding are genes associated with intracellular calcium homeostasis such as pumps and transporters, 
voltage-gated calcium channels and sodium channels, potassium channels as well as synaptic receptors (Oksenberg et al., 2014). One of the targets of AUTS2 binding, the voltage-gated calcium channel subunit cacna2d2 is known to regulate the calcium current density and the activation/inactivation kinetics of $P / Q$ type, L-type, Ntype and T-type calcium channels. Mutations in voltage-dependent calcium channels are known to associate with ASDs (Krey and Dolmetsch, 2007; Heyes et al., 2015; Lory et al., 2020). Loss of Auts2a in zebrafish could potentially reduce M-cell excitability via dysregulation of intracellular calcium homeostasis and by directly affecting calcium channel function during depolarization. Another important pair of targets of AUTS2 binding are Kcnip1 and Kcnip4, which are potassium channel interacting proteins (Oksenberg et al., 2014). These proteins contain an EF-hand domain, sense intracellular calcium and regulate A-type transient potassium currents. A-type potassium channels are critical determinants of firing threshold and latency. Lastly, Auts2 binding is also seen within genes coding for a number of voltage-gated potassium channels (Oksenberg et al., 2014). Thus, loss of Auts2a might interfere with expression levels of one or more of these targets leading to hypoexcitability of M-cells. Wherever it is expressed, Auts2 might be essential for determining neuronal excitability by setting levels of expression of ion channel genes or their regulatory partners. Manipulations that reduce global activity levels of neurons in culture lead to homeostatic resetting of intrinsic and synaptic properties (Turrigiano et al., 1998; Desai, 2003; Turrigiano and Nelson, 2004), a process that requires transcription (Ibata et al., 2008). Recently, it was shown that manipulations that induce homeostatic plasticity also trigger significant upregulation of AUTS2 expression (Schaukowitch et al., 2017). Thus, on the basis of our study and these 
earlier studies, we posit that Auts2 is important for setting and maintaining the excitability set-points of neurons.

\section{Alterations in neuronal excitability and ASDs}

Since ASDs are frequently also comorbid with epilepsy, and because mutations that reduce inhibition or increase excitation frequently associate with them, ASDs were initially thought to result from hyperexcitation in the central nervous system (Rubenstein and Merzenich, 2003). However, it is becoming clear that balance between excitation and inhibition is key and when that balance is tilted towards more excitation or more inhibition, network function is impaired leading to ASD-like phenotypes (Nelson and Valakh, 2015; Lee et al., 2017; Sohal and Rubenstein, 2019). Activity imaging using expression of the immediate early gene $c$-Fos reveals hypoactivity in much of the forebrain in a mouse model of Rett syndrome (Kron et al., 2012). Reduced connectivity and reduced activation of forebrain structures at rest have also been reported in $\mathrm{fMRI}$ studies of human autistic subjects (Minshew and Keller, 2010). These studies underline the fact that since ASDs are associated with mutations in multiple genetic pathways, they should be thought of as diseases resulting from abnormal excitation to inhibition balance. Consistent with this view, a recent study demonstrates that in Auts2 mutant mice, hippocampal pyramidal neurons receive increased excitatory synaptic inputs with no change in the amount of inhibition received, upsetting the excitation to inhibition balance (Hori et al., 2020). We have shown that loss of function of Auts2a in zebrafish leads to hypoexcitability in an identified neuron, the M-cell, which is responsible for driving fast escapes. Our identification of this specific deficit in an identified neuron in a circuit with defined behavioral function is significant as it pinpoints to specific cellular mechanisms due 
to which excitation to inhibition balance is altered in the autistic brain. Taking these studies together, Auts2/Auts2a might play circuit specific functions in maintaining the excitation to inhibition balance by triggering transcriptional programs for the expression of specific combinations of ion channels and synaptic receptors.

\section{Author Contributions}

U.J., I.K. and V.T., conception and design; U.J. acquisition and analysis of behavior and imaging data; I.K., generation of the mutant lines; V.K., and V.T., funding acquisition and resources; U.J., I.K. and V.T., drafting the manuscript.

\section{Materials and Methods}

\section{Fish care and use}

Zebrafish (Danio rerio) of $\mathrm{AB}$ strain and Indian wild type were housed in aquarium tanks at $28.5^{\circ} \mathrm{C}$ with a $14: 10$ hours light:dark cycle. Fish were maintained according to established protocols as previously described (Westerfield, 2000) in agreement with the Institutional Animal Ethics Committee and the Institutional Biosafety Committee, National Centre for Biological Sciences. For fin amputation, fish were briefly anaesthetized in $0.01 \%$ Tricaine (MS-222, Sigma-Aldrich), the caudal fin was cut and fish were immediately returned to fresh water. Experiments were performed on 6-8 days post fertilization (dpf) larval zebrafish at room temperature. Larvae were maintained in $14: 10$ light-dark cycle at $28^{\circ} \mathrm{C}$ in $\mathrm{E} 3$ medium ( $5 \mathrm{mM} \mathrm{NaCl}, 0.17 \mathrm{mM} \mathrm{KCl}, 0.33 \mathrm{mM} \mathrm{CaCl}_{2}$ and $0.33 \mathrm{mM} \mathrm{MgSO}$, $\mathrm{pH}$ 7.8). Larvae were treated with $0.003 \%$ 1-phenyl-2-thiourea in 10\% Hank's saline at $24 \mathrm{hpf}$ to remove pigments, for calcium imaging experiments. 


\section{TALEN design, construction and synthesis}

TALENs specific to auts2a were manually designed using criteria as described previously (Bedell et al., 2012) and assembled according to the established protocol (Sanjana et al., 2012). The plasmid kit used for building TALENs was a gift from Dr. Feng Zhang (Addgene kit \#1000000019). Once assembled into a destination vector, TALENs then were re-cloned into pTNT vector (Promega) containing synthetic polyA tail and T7 terminator sequence. The auts2a TALEN recognition sequences are as follows: left TALEN, CCAGCTGGGAGTGCCT and right TALEN, GTAATAGCACTTTAGGTGG. Between the two binding sites is a

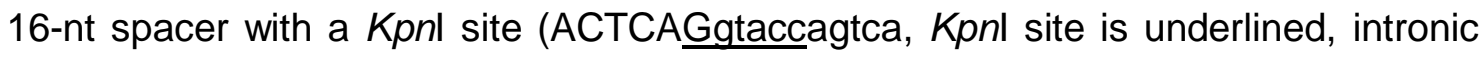
sequence is in lower case), facilitating identification of mutations by PCR and Kpnl restriction digestion. The spacer region overlaps with the donor splice site at exon 8 (Figure 1A). Capped mRNA was synthesized by in vitro transcription using mMESSAGE mMACHINE T7 kit (Invitrogen) and purified with RNeasy Mini kit (Qiagen). Zebrafish embryos at the 1-cell stage were microinjected with 200 pg RNA (100 pg each of left and right TALEN mRNA). At such a dose, over $70 \%$ embryos survived and showed TALEN-induced somatic auts2a gene modifications.

\section{DNA isolation and genotyping}

Genomic DNA was isolated from either embryos or fin clips using HotSHOT method (Meeker et al., 2007). One microliter solution was then used in a 25/L PCR containing the following reagents at these concentrations: $200 \mathrm{nM}$ each genespecific primers (forward 5'-TCAGCGAACCCTACAGCTTCACACA-3' and reverse 5'-TGGGGTACGCACCATGGGCGGTGCA-3'), 0.2 mM dNTPs, 1xPCR buffer and 
0.625 units One Taq HotStart DNA polymerase (New England BioLabs). Reaction was amplified using the following conditions: $94^{\circ} \mathrm{C}$ for $1 \mathrm{~min} ; 40$ cycles of $94^{\circ} \mathrm{C}$ for 20 $\mathrm{s}, 68^{\circ} \mathrm{C}$ for $1 \mathrm{~min}$; followed by $68^{\circ} \mathrm{C}$ for $1 \mathrm{~min}$. PCR products were purified using PCR purification kit (Qiagen) and digested with restriction enzyme Kpnl-HF (New England BioLabs) at $37^{\circ} \mathrm{C}$ for $60 \mathrm{~min}$. The resulting reactions were loaded onto a $1.8 \%$ agarose gel and electrophoresed in 1x Tris-acetate-EDTA (TAE) buffer. Mutations were assessed by loss of restriction enzyme digestion. To verify mutations, the gel purified uncut PCR products were cloned into pCRII-TOPO vector (TOPO TA Cloning kit, Invitrogen) and sequenced.

\section{RT-PCR and RNA isolation}

Total RNA was isolated from wild type and auts $2 a^{\text {ncb104 }}$ heterozygote and homozygote embryos using an RNeasy Mini kit (QIAGEN), and first-strand cDNA was synthesized from 1 (g of total RNA by oligo(dT) priming using SMARTScribe Reverse Transcriptase (Clontech) according to the manufacturer's protocol. Amplification of cDNA was performed using Herculase II Fusion DNA polymerase (Agilent). Identity of amplified PCR products was verified by direct sequencing.

\section{Whole-mount Immunohistochemistry}

Embryos were fixed in $4 \%$ PFA at $4^{\circ} \mathrm{C}$ overnight, washed 3 times for 15 min in PBST ( $1 \times$ PBS, $0.1 \%$ Tween-20) and permeabilized in $0.1 \%$ Triton $X-100$ in $0.1 \%$ sodium citrate for $30 \mathrm{~min}$ at $4^{\circ} \mathrm{C}$. Then embryos were incubated for 2 hours in $5 \%$ Blocking Reagent (Roche) in MAB (150 mM maleic acid, pH 7.5, $100 \mathrm{mM} \mathrm{NaCl,} \mathrm{0.1 \%} \mathrm{Tween-}$ 20) at room temperature. Embryos were incubated with $3 A 10$ antibodies (DSHB, 
1:200) overnight at $4^{\circ} \mathrm{C}$, washed 4 times for 30 min in MAB and incubated with HRPconjugated goat anti-mouse $F(a b)_{2}$ fragments (Molecular Probe, 1:500) for 6 hours at room temperature or overnight at $4^{\circ} \mathrm{C}$. Embryos were extensively washed in PBST, stained with 3,3'-diaminobenzidine (DAB) and washed several times in PBST. Embryos were kept in $50 \%$ glycerol in PBS at $4^{\circ} \mathrm{C}$ until further imaging.

\section{Head restrained preparation}

For behaviour and calcium imaging experiments, larvae were embedded in $2 \%$ low gelling agarose (Sigma-Aldrich, Missouri, USA). E3 medium was added after the agarose congealed. Agarose around the tail and the otic vesicle (OV) were removed for observing tail movements and application of water pulse for behavioural experiments.

\section{High-speed recording of escape response}

Escape responses were evoked by applying a water pulse to the OV or to the tail at the level of cloaca, with a glass capillary (tip diameter $0.05-0.06 \mathrm{~mm}$ ) mounted on a micromanipulator (Narishige; Tokyo, Japan). The water pulses were generated by a pressure pulse of $10 \mathrm{~ms}$ duration and pressure of 30 psi from microinjection dispense system (Picospritzer III, Parker Hannifin, Ohio, USA). Videos were acquired at 1000 fps with a high speed camera (Phantom Miro eX4, Vision research, New Jersey, USA) mounted on a stereo microscope (SZX16, Olympus, Tokyo, Japan) at $512 \times 512$ pixel resolution and $500 \mu$ s exposure time. Methylene blue (1\%) was used to visualize the water jet for tracking its contact with the larva. Six trials (three on each side) were performed on each larva. 


\section{Retrograde labelling of Mauthner neurons}

Mauthner neurons were retrogradely labelled with fluorescent calcium indicator Oregon Green Bapta-1 dextran, 10000 mW (Invitrogen, California, USA). Larvae were first anaesthetised in $0.01 \%$ MS-222 (Sigma Aldrich; Missouri,USA) in E3 medium. 25\% OGB-1 in 10\% Hank's Balanced Salt Solution (HBSS; $137 \mathrm{mM} \mathrm{NaCl}$, $5.4 \mathrm{mM} \mathrm{KCl}, 0.25 \mathrm{mM} \mathrm{Na}_{2} \mathrm{HPO}_{4}, 0.44 \mathrm{mM} \mathrm{KH}_{2} \mathrm{PO}_{4}, 1.3 \mathrm{mM} \mathrm{CaCl}_{2}, 1.0 \mathrm{mM} \mathrm{MgSO}$, $4.2 \mathrm{mM} \mathrm{NaHCO}_{3}$ ) was pressure injected with a glass microcapillary into the spinal cord (at the level of cloaca) using a Picospritzer. Post injection, larvae were allowed to recover in HBSS for $>12 \mathrm{~h}$.

\section{Electrical stimulation}

Electric shock stimuli (40 $\mathrm{AA}, 1 \mathrm{~ms})$ were delivered using a bipolar electrode (FHC, Bowdoin, ME, USA) placed at the OV. The pulse was generated using ISO-Flex stimulus isolator (A.M.P.I., Jerusalem, Israel), triggered by pClamp (Molecular devices, California, USA). For antidromic stimulation of the M-axon, larvae were anaesthetized in 0.01\% MS-222 (Sigma-Aldrich; Missouri, USA) and were pinned down through notochord using fine tungsten wire (California Fine Wire). The MS222 was then replaced by external solution (composition: $134 \mathrm{mM} \mathrm{NaCl}, 2.9 \mathrm{mM} \mathrm{KCl}, 1.2$ $\mathrm{mM} \mathrm{MgCl} 2,10 \mathrm{mM}$ HEPES, $10 \mathrm{mM}$ glucose, 2.1 $\mathrm{mM} \mathrm{CaCl}_{2}, 0.01 \mathrm{mM}$ D-tubocurarin; $\mathrm{pH} 7.8 ; 290$ mOsm) and skin along the tail was carefully removed using forceps (Fine Science Tools, Foster City, USA). Muscles in a hemi-segment (between the $10^{\text {th }}$ and $13^{\text {th }}$ myotomes) were carefully removed to expose the spinal cord. The bipolar electrode was placed on top of the exposed spinal segment and brief electrical stimuli of increasing strengths (10 $\mu \mathrm{A}$ onwards, $1 \mathrm{~ms}$ in duration) were delivered. 


\section{Calcium imaging}

Calcium activity upon electrical stimulation of OV/M-axon, in retrogradely labelled Mauthner neurons, was imaged at 35-45 frames per second using an EMCCD camera (Evolve, Photometrics, UK) mounted on a compound microscope (BX61W1, Olympus, Tokyo, Japan) with a water-immersion objective (LUMPlanFL 60X) and Image-Pro Plus (Media Cybernetics, UK) acquisition software.

\section{Analysis}

Data were analysed using MATLAB (Mathworks; Massachusetts, USA) and Fiji (NIH).

\section{Behavioural analysis}

Latency was defined as the time taken from when the water jet made contact with the larva to the first visible tail contraction. Tail bend angle was calculated by measuring the angle formed by joining a straight line passing through the tail at maximum bend and a straight line passing through the head and the tail in a prestimulus frame (Figure 2C). Escape responses were defined as contralateral tail bends with latency $\leq 100 \mathrm{~ms}$ (Kimmel et al., 1974; Kohashi and Oda, 2008). Tail 
bend responses with latency $>100 \mathrm{~ms}$ or no observable tail bend upto $1 \mathrm{~s}$ post stimulus delivery were classified as failures ('no response').

\section{Calcium activity analysis}

Relative changes in fluorescence from resting $(\Delta F / F)$ were calculated post background and movement correction. Activity in Mauthner neurons was considered to have occurred only for $\Delta F / F$ traces with minimum peak $\Delta F / F$ of 0.1 and full width at half maximum of at least $1 \mathrm{~s}$. Threshold for antidromic stimulation of Mauthner was defined as the minimum stimulus intensity at which the Mauthner neuron showed calcium activity for all trials at the given stimulus intensity.

Dendritic length and soma volume of Mauthner neurons were measured using simple neurite tracer and volume viewer plugins in Fiji (Schindelin et al., 2012).

\section{Statistics}

Data were tested for normality using one sample Kolmogorov-Smirnov test $(p<0.05)$ and equality of variance with $F$ test $(\mathrm{p}<0.05)$. Two sample t-test or Mann-Whitney $U$ test were performed for comparisons between two groups and Kruskal-Wallis test was used for comparing three groups. Chi-square test was performed for comparison of proportions. 


\section{Figure legends}

\section{Figure 1. TALEN-induced mutation in auts2a gene.}

(A) Zebrafish autsza gene locus, TALEN target sites and isolated alleles. The TALENs target a pair of binding sites (in blue) flanking a spacer with a restriction enzyme site (in green). Exonic and intronic sequences are shown in upper and lower cases, respectively. In contrast to genomic sequence annotated in the Ensembl (WT), our "in-house" zebrafish $A B$ strain $\left(W^{*}\right)$ has a polymorphism in intronic sequence adjacent to exon 8 (in red). Alleles ncb101, ncb103, ncb104 and ncb105 have the nucleotide deletions that disrupt the donor splice site (in bold) leading to a frameshift after S498 and premature stop codons. Deletion in allele ncb102 does not affect a correct splicing and Auts2 protein sequence. Three single point mutations were introduced in intron of auts $2 a^{n c b 104}$ allele (in orange) leading to a stop codon creation (underlined). The alternative donor splice sites used to splice a mutant auts $2 a^{\text {ncb104 }}$ pre-mRNA are highlighted in grey.

(B, top) Auts2a and Auts2a $\mathrm{a}^{\text {ncb104 }}$ proteins. The ncb104 mutation causes the loss of the C-terminal portion of Auts2a, comprising PY motif, proline-rich region PR2 and the Auts2 family domain. (B, bottom left) RT-PCR analysis of auts2a mRNA, isolated from wild type (WT), ncb104 heterozygote (HET) and homozygote (MUT) embryos. M, 100-bp DNA ladder (NEB). (B, bottom right) Partial protein sequences of mutant alleles.

Figure 2. Onset of escape response is delayed and highly variable in auts2a mutants.

(A) Schematic of experimental set up and escape circuit. Escape response was evoked in zebrafish larvae (6-8 dpf) by directing a strong water-jet at the otic vesicle 
(OV) activating ipsilateral Mauthner (M-cell) and its segmental homologs, MiD2cm and MiD3cm. Escape response is characterised by a large angle tail deflection, contralateral to the direction of water-jet.

(B) Time lapse of escape response. 1. Pre-stimulus frame. 2. Water jet makes first contact with OV. 3. First visible tail contraction (marked with asterisk). 4. Representative frame showing references used for maximum tail bend angle calculation.

(C) Pie chart showing percentage of contralateral, ipsilateral and no tail bend responses observed across wild type ( $n=143$ trials), heterozygotes ( $n=258$ trials) and auts2a mutants ( $\mathrm{n}=371$ trials).

(D) Escape latencies across successive trials from five wild type and mutant larvae. Color bar represents escape latencies. NR: no response.

(E) Comparison of escape response latencies in wild type (WT), heterozygotes (HET) and auts2a mutants (MUT). $\mathrm{n}_{\mathrm{WT}}=140$ trials from 24 larvae, $\mathrm{n}_{\mathrm{HET}}=254$ trials from 43 larvae and $\mathrm{n}_{\mathrm{MUT}}=292$ trials from 57 larvae.

(F) Cumulative density function plot for short-latency escapes (latencies $\leq 20 \mathrm{~ms}$ ) in wild type ( $\mathrm{n}=140$ trials), heterozygotes (254 trials), and auts2a mutants $(\mathrm{n}=273$ trials).

(G) Coefficient of variation of latencies across successive trials in individual larva for wild type $(n=24)$, heterozygotes $(n=43)$ and mutants $(n=53)$ groups.

(H) Comparison of maximum tail bend angle of contralateral turn between the three groups ( $\mathrm{n}=140$ trials, WT; 254 trials, HET; 281 trials, mutants). Kruskal Wallis; Mann-Whitney test for between-groups comparisons with Bonferroni correction for multiple comparisons. ${ }^{*} p<0.025,{ }^{* *} p<0.005,{ }^{* * *} p<0.0005$; ns, not significant. 
Figure 3. Escape response defects in auts2a mutants persist on changing the location of sensory stimulation

(A) Schematic of experimental set up and escape circuit. Tail stimulation activates ipsilateral Mauthner but not its homologs and contralateral M-series.

(B) Time lapse of escape response evoked by tail stimulation. 1. Pre-stimulus frame.

2. Water jet makes first contact with the tail. 3. First visible tail contraction (marked with asterisk). 4. Representative frame for maximum tail bend angle calculation.

(C) Pie chart showing percentage of contralateral tail bends, ipsilateral tail bends and failures to initiate an escape response between wild type ( $n=58$ trials) and mutants $(\mathrm{n}=84$ trials $)$.

(D) Comparison of escape response latencies on tail stimulation between wild type ( $n=48$ trials, 10 larvae) and auts $2 a$ mutants ( $n=50$ trials, 15 larvae).

(E) Comparison of coefficient of variation of latencies across successive trials for each larva between wild type $(n=10)$ and mutant $(n=13)$ groups.

(F) Maximum tail bend angle of turns for WT ( $n=48$ trials) and mutants ( $n=54$ trials). ${ }^{*} p<0.05,{ }^{* *} p<0.0001 ;$ ns, not significant.

Fig 4. Mauthner neuron fails to fire reliably in auts2a mutants

(A) Schematic representation of experimental set up. Mauthner

neuron was retrogradely labelled with OGB-1 dextran and calcium activity was monitored upon electrical stimulation $(40 \mu \mathrm{A}, 1 \mathrm{~ms})$ of $\mathrm{OV}$.

(B) Left : Raster plot of all trials in WT ( $\mathrm{n}=68$ trials; 10 larvae) showing consistent calcium activity across several trials on OV stimulation.

Right : Calcium responses observed across all trials in the mutant group (80 trials; 14 larvae). White line represents time of stimulus delivery. 
(C) Top: $\Delta F / F$ profile of a Mauthner neuron in an example wild type larva across 8

trials in response to electrical stimulation of the OV. Bottom: $\Delta F / F$ profile of a

Mauthner neuron in an example auts2a mutant larva showing sub-threshold

response as well large calcium transients across 8 trials upon electrical stimulation of OV.

(D) Probability of calcium activity response across trials per larva ( $\mathrm{n}_{\mathrm{WT}}=10$ larvae, $\mathrm{n}_{\mathrm{MUT}}=14$ larvae).

(E) Peak $\Delta F / F$ in WT and mutants ( $n_{W T}=68$ trials, $n_{M U T}=80$ trials).

(F) Comparison of coefficient of variation of peak $\Delta F / F$ between wild type and mutant larvae.

Mann-Whitney U test; ${ }^{* *} p<0.0001$.

Fig. 5. Mauthner neuron in auts2a mutants have reduced excitability

(A) Schematic of experimental set-up. Calcium activity in Mauthner neuron was observed on antidromic stimulation. Mauthner neuron was retrogradely labelled with OGB-1 dextran.

(B) $\Delta F / F$ profile for an example wild type larva upon antidromic stimulation with $10 \mu \mathrm{A}$

(left) and $20 \mu \mathrm{A}$ (right) stimulus intensity. Mauthner neuron fired reliably at the threshold intensity of $20 \mu \mathrm{A}$. 
(C) Representative raster plot from a wild type larva (left) and mutant larva (D) Each

row represents average $\Delta \mathrm{F} / \mathrm{F}$ over five trials at respective stimulus intensity. The

threshold for calcium activity for wild type larva is $20 \mu \mathrm{A}$ whereas for the mutant larva

is $70 \mu \mathrm{A}$.

(E) Normalised histogram of calcium activity threshold for auts2a mutants $(n=12$ larvae) and WT ( $\mathrm{n}=9$ larvae).

(F) Summary data of probability of calcium activity at $0.5,1,1.5 \mathrm{X}$ threshold stimulus intensity for wild type and mutant group.

(G) $\Delta F / F$ profiles for a representative wild type larva (black) and a mutant larva (red)

on antidromic stimulation. Shaded regions represents SEM from five trials.

(H) Summary data of peak calcium signal in wild type ( $\mathrm{n}=45$ trials, 9 larvae) and auts2a mutants ( $\mathrm{n}=60$ trials, 12 larvae).

${ }^{*} p<0.05,{ }^{* *} p<0.001 ;$ Mann-Whitney $U$ test

Figure 6. Summary of behavioural abnormalities in escape response in auts2a mutants.

Top: In response to threatening stimuli ipsilateral Mauthner and its homologs in the hindbrain (marked in dashed box) fire reliably (yellow) resulting in short latency escape responses across consecutive trials in wild type larvae.

Bottom: Reduced excitability of Mauthner neurons and homologs in mutants results in decreased probability of firing an action potential and variable behavioral 
bioRxiv preprint doi: https://doi.org/10.1101/2020.11.04.367821. this version posted November 4, 2020. The copyright holder for this preprint (which was not certified by peer review) is the author/funder, who has granted bioRxiv a license to display the preprint in perpetuity. It is made available under aCC-BY-NC-ND 4.0 International license.

responses (short latency escape response, longer latency non-Mauthner mediated escape response and no response) across consecutive trials. 


\section{Reference:}

Bedell VM, Wang Y, Campbell JM, Poshusta TL, Starker CG, Krug li RG, Tan W, Penheiter SG, Ma AC, Leung AYH, Fahrenkrug SC, Carlson DF, Voytas DF, Clark KJ, Essner JJ, Ekker SC. 2012. In vivo genome editing using a high-efficiency TALEN system. Nature 491:114-118. doi:10.1038/nature11537

Bedogni F, Hodge RD, Nelson BR, Frederick EA, Shiba N, Daza RA, Hevner RF. 2010. Autism susceptibility candidate 2 (Auts2) encodes a nuclear protein expressed in developing brain regions implicated in autism neuropathology. Gene Expression Patterns 10:9-15. doi:10.1016/j.gep.2009.11.005

Beunders G, Voorhoeve E, Golzio C, Pardo LM, Rosenfeld JA, Talkowski ME, Simonic I, Lionel AC, Vergult S, Pyatt RE, van de Kamp J, Nieuwint A, Weiss MM, Rizzu $P$, Verwer LENI, van Spaendonk RML, Shen Y, Wu B, Yu T, Yu Y, Chiang C, Gusella JF, Lindgren AM, Morton CC, van Binsbergen $E$, Bulk $S$, van Rossem $E$, Vanakker $O$, Armstrong R, Park S-M, Greenhalgh L, Maye U, Neill NJ, Abbott KM, Sell S, Ladda R, Farber DM, Bader PI, Cushing T, Drautz JM, Konczal L, Nash P, de Los Reyes E, Carter MT, Hopkins E, Marshall CR, Osborne LR, Gripp KW, Thrush DL, Hashimoto S, Gastier-Foster JM, Astbury C, Ylstra B, Meijers-Heijboer H, Posthuma D, Menten B, Mortier G, Scherer SW, Eichler EE, Girirajan S, Katsanis N, Groffen AJ, Sistermans EA. 2013. Exonic Deletions in AUTS2 Cause a Syndromic Form of Intellectual Disability and Suggest a Critical Role for the C Terminus. The American Journal of Human Genetics 92:210-220. doi:10.1016/j.ajhg.2012.12.011

Bourgeron T. 2015. From the genetic architecture to synaptic plasticity in autism spectrum disorder. Nature Reviews Neuroscience 16:551-563. doi:10.1038/nrn3992

Brewster DL, Ali DW. 2013. Expression of the voltage-gated potassium channel subunit Kv1.1 in embryonic zebrafish Mauthner cells. Neuroscience Letters 539:54-59. doi:10.1016/j.neulet.2013.01.042

Burgess HA, Granato M. 2007. Sensorimotor Gating in Larval Zebrafish. J Neurosci 27:49844994. doi:10.1523/JNEUROSCl.0615-07.2007

Burgess HA, Johnson SL, Granato M. 2009. Unidirectional startle responses and disrupted left-right co-ordination of motor behaviors in robo3 mutant zebrafish. Genes Brain Behav 8:500-511. doi:10.1111/j.1601-183X.2009.00499.X

De Rubeis S, He X, Goldberg AP, Poultney CS, Samocha K, Ercument Cicek A, Kou Y, Liu L, Fromer M, Walker S, Singh T, Klei L, Kosmicki J, Fu S-C, Aleksic B, Biscaldi M, Bolton PF, Brownfeld JM, Cai J, Campbell NG, Carracedo A, Chahrour MH, Chiocchetti AG, Coon H, Crawford EL, Crooks L, Curran SR, Dawson G, Duketis E, Fernandez BA, Gallagher L, Geller E, Guter SJ, Sean Hill R, Ionita-Laza I, Jimenez Gonzalez P, Kilpinen $\mathrm{H}$, Klauck SM, Kolevzon A, Lee I, Lei J, Lehtimäki T, Lin C-F, Ma'ayan A, Marshall CR, Mclnnes AL, Neale B, Owen MJ, Ozaki N, Parellada M, Parr JR, Purcell S, Puura K, Rajagopalan D, Rehnström K, Reichenberg A, Sabo A, Sachse $M$, Sanders SJ, Schafer C, Schulte-Rüther $M$, Skuse D, Stevens $C$, Szatmari $P$, Tammimies K, Valladares $O$, Voran A, Wang L-S, Weiss LA, Jeremy Willsey A, Yu TW, Yuen RKC, Cook EH, Freitag CM, Gill M, Hultman CM, Lehner T, Palotie A, Schellenberg GD, Sklar P, State MW, Sutcliffe JS, Walsh CA, Scherer SW, Zwick ME, Barrett JC, Cutler DJ, Roeder K, Devlin B, Daly MJ, Buxbaum JD. 2014. Synaptic, transcriptional and chromatin genes disrupted in autism. Nature 515:209-215. doi:10.1038/nature13772 
Desai NS. 2003. Homeostatic plasticity in the CNS: synaptic and intrinsic forms. Journal of Physiology-Paris, Neuroscience and Computation 97:391-402. doi:10.1016/j.jphysparis.2004.01.005

Eaton RC, Bombardieri RA, Meyer DL. 1977. The Mauthner-initiated startle response in teleost fish. J Exp Biol 66:65-81.

Eaton RC, Farley RD. 1975. Mauthner neuron field potential in newly hatched larvae of the zebra fish. J Neurophysiol 38:502-512. doi:10.1152/jn.1975.38.3.502

Eaton RC, Lavender WA, Wieland CM. 1981. Identification of Mauthner-initiated response patterns in goldfish: Evidence from simultaneous cinematography and electrophysiology. J Comp Physiol 144:521-531. doi:10.1007/BF01326837

Eaton RC, Lee RKK, Foreman MB. 2001. The Mauthner cell and other identified neurons of the brainstem escape network of fish. Progress in Neurobiology 63:467-485. doi:10.1016/S0301-0082(00)00047-2

Eaton RC, Nissanov J, Wieland CM. 1984. Differential activation of Mauthner and nonMauthner startle circuits in the zebrafish: Implications for functional substitution. $J$ Comp Physiol 155:813-820. doi:10.1007/BFo0611598

Fetcho JR. 1991. Spinal network of the Mauthner cell. Brain Behav Evol 37:298-316. doi:10.1159/000114367

Gahtan E, Baier H. 2004. Of lasers, mutants, and see-through brains: functional neuroanatomy in zebrafish. J Neurobiol 59:147-161. doi:10.1002/neu.20000

Gao Z, Lee P, Stafford JM, von Schimmelmann M, Schaefer A, Reinberg D. 2014. An AUTS2-Polycomb complex activates gene expression in the CNS. Nature 516:349354. doi:10.1038/nature13921

Granato M, Eeden FJ van, Schach U, Trowe T, Brand M, Furutani-Seiki M, Haffter $P$, Hammerschmidt $M$, Heisenberg CP, Jiang YJ, Kane DA, Kelsh RN, Mullins MC, Odenthal J, Nusslein-Volhard C. 1996. Genes controlling and mediating locomotion behavior of the zebrafish embryo and larva. Development 123:399-413.

Heyes S, Pratt WS, Rees E, Dahimene S, Ferron L, Owen MJ, Dolphin AC. 2015. Genetic disruption of voltage-gated calcium channels in psychiatric and neurological disorders. Prog Neurobiol 134:36-54. doi:10.1016/j.pneurobio.2015.09.002

Hori K, Hoshino M. 2017. Neuronal Migration and AUTS2 Syndrome. Brain Sciences 7:54. doi:10.339o/brainsci7050054

Hori K, Nagai T, Shan W, Sakamoto A, Taya S, Hashimoto R, Hayashi T, Abe M, Yamazaki M, Nakao K, Nishioka T, Sakimura K, Yamada K, Kaibuchi K, Hoshino M. 2014. Cytoskeletal regulation by AUTS2 in neuronal migration and neuritogenesis. Cell Rep 9:2166-2179. doi:10.1016/j.celrep.2014.11.045

Hori K, Yamashiro K, Nagai T, Shan W, Egusa SF, Shimaoka K, Kuniishi H, Sekiguchi M, Go Y, Tatsumoto S, Yamada Mitsuyo, Shiraishi R, Kanno K, Miyashita S, Sakamoto A, Abe M, Sakimura K, Sone M, Sohya K, Kunugi H, Wada K, Yamada Mitsuhiko, Yamada K, Hoshino M. 2020. AUTS2 Regulation of Synapses for Proper Synaptic Inputs and Social Communication. iScience 23:101183. doi:10.1016/j.isci.2020.101183

Ibata K, Sun Q, Turrigiano GG. 2008. Rapid Synaptic Scaling Induced by Changes in Postsynaptic Firing. Neuron 57:819-826. doi:10.1016/j.neuron.2008.02.031

Jain RA, Wolman MA, Marsden KC, Nelson JC, Shoenhard H, Echeverry FA, Szi C, Bell H, Skinner J, Cobbs EN, Sawada K, Zamora AD, Pereda AE, Granato M. 2018. A Forward Genetic Screen in Zebrafish Identifies the G-Protein-Coupled Receptor 
CaSR as a Modulator of Sensorimotor Decision Making. Curr Biol 28:1357-1369.e5. doi:10.1016/j.cub.2018.03.025

Kalscheuer VM, FitzPatrick D, Tommerup N, Bugge M, Niebuhr E, Neumann LM, Tzschach A, Shoichet SA, Menzel C, Erdogan F, Arkesteijn G, Ropers H-H, Ullmann R. 2007. Mutations in autism susceptibility candidate 2 (AUTS2) in patients with mental retardation. Hum Genet 121:501-509. doi:10.1007/s00439-006-0284-0

Kimmel CB, Patterson J, Kimmel RO. 1974. The development and behavioral characteristics of the startle response in the zebra fish. Developmental Psychobiology 7:47-60. doi:10.1002/dev.420070109

Kimmel CB, Powell SL, Metcalfe WK. 1982. Brain neurons which project to the spinal cord in young larvae of the zebrafish. Journal of Comparative Neurology 205:112-127. doi:10.1002/cne.902050203

Kohashi T, Nakata N, Oda Y. 2012. Effective Sensory Modality Activating an Escape Triggering Neuron Switches during Early Development in Zebrafish. J Neurosci 32:5810-5820. doi:10.1523/JNEUROSCl.6169-11.2012

Kohashi T, Oda Y. 2008. Initiation of Mauthner- or Non-Mauthner-Mediated Fast Escape Evoked by Different Modes of Sensory Input. J Neurosci 28:10641-10653. doi:10.1523/JNEUROSCl.1435-08.2008

Kondrychyn I, Robra L, Thirumalai V. 2017. Transcriptional Complexity and Distinct Expression Patterns of auts2 Paralogs in Danio rerio. G3 (Bethesda) 7:2577-2593. doi:10.1534/93.117.042622

Korn H, Faber DS. 2005. The Mauthner Cell Half a Century Later: A Neurobiological Model for Decision-Making? Neuron 47:13-28. doi:10.1016/j.neuron.2005.05.019

Krey JF, Dolmetsch RE. 2007. Molecular mechanisms of autism: a possible role for Ca2+ signaling. Current Opinion in Neurobiology, Development 17:112-119. doi:10.1016/j.conb.2007.01.010

Kron M, Howell CJ, Adams IT, Ransbottom M, Christian D, Ogier M, Katz DM. 2012. Brain Activity Mapping in Mecp2 Mutant Mice Reveals Functional Deficits in Forebrain Circuits, Including Key Nodes in the Default Mode Network, that are Reversed with Ketamine Treatment. J Neurosci 32:13860-13872. doi:10.1523/JNEUROSCI.215912.2012

Lee E, Lee J, Kim E. 2017. Excitation/Inhibition Imbalance in Animal Models of Autism Spectrum Disorders. Biological Psychiatry 81:838-847. doi:10.1016/j.biopsych.2016.05.011

Liu KS, Fetcho JR. 1999. Laser Ablations Reveal Functional Relationships of Segmental Hindbrain Neurons in Zebrafish. Neuron 23:325-335. doi:10.1016/So8966273(00)80783-7

Lorent K, Liu KS, Fetcho JR, Granato M. 2001. The zebrafish space cadet gene controls axonal pathfinding of neurons that modulate fast turning movements. Development 128:2131-2142.

Lory P, Nicole S, Monteil A. 2020. Neuronal Cav3 channelopathies: recent progress and perspectives. Pflugers Arch - Eur J Physiol 472:831-844. doi:10.1007/s00424-02002429-7

Marquart GD, Tabor KM, Bergeron SA, Briggman KL, Burgess HA. 2019. Prepontine nongiant neurons drive flexible escape behavior in zebrafish. PLOS Biology 17:e3000480. doi:10.1371/journal.pbio.3000480 
Marsden KC, Jain RA, Wolman MA, Echeverry FA, Nelson JC, Hayer KE, Miltenberg B, Pereda AE, Granato M. 2018. A Cyfipz-Dependent Excitatory Interneuron Pathway Establishes the Innate Startle Threshold. Cell Rep 23:878-887. doi:10.1016/j.celrep.2018.03.095

Meeker ND, Hutchinson SA, Ho L, Trede NS. 2007. Method for isolation of PCR-ready genomic DNA from zebrafish tissues. BioTechniques 43:610-614. doi:10.2144/000112619

Metcalfe WK, Mendelson B, Kimmel CB. 1986. Segmental homologies among reticulospinal neurons in the hindbrain of the zebrafish larva. Journal of Comparative Neurology 251:147-159. doi:10.1002/cne.902510202

Minshew NJ, Keller TA. 2010. "The Nature of Brain Dysfunction in Autism: Functional Brain Imaging Studies." Curr Opin Neurol 23:124-130. doi:10.1097/WCO.obo13e32833782d4

Nakayama H, Oda Y. 2004. Common Sensory Inputs and Differential Excitability of Segmentally Homologous Reticulospinal Neurons in the Hindbrain. J Neurosci 24:3199-3209. doi:10.1523/JNEUROSCl.4419-03.2004

Nelson SB, Valakh V. 2015. Excitatory/Inhibitory Balance and Circuit Homeostasis in Autism Spectrum Disorders. Neuron 87:684-698. doi:10.1016/j.neuron.2015.07.033

Oksenberg N, Ahituv N. 2013. The role of AUTS2 in neurodevelopment and human evolution. Trends in Genetics 29:600-608. doi:10.1016/j.tig.2013.08.001

Oksenberg N, Haliburton GDE, Eckalbar WL, Oren I, Nishizaki S, Murphy K, Pollard KS, Birnbaum RY, Ahituv N. 2014. Genome-wide distribution of Auts2 binding localizes with active neurodevelopmental genes. Translational Psychiatry 4:e431-e431. doi:10.1038/tp.2014.78

Rubenstein JLR, Merzenich MM. 2003. Model of autism: increased ratio of excitation/inhibition in key neural systems. Genes, Brain and Behavior 2:255-267. doi:10.1034/j.1601-183X.2003.00037.x

Russo D, Della Ragione F, Rizzo R, Sugiyama E, Scalabri F, Hori K, Capasso S, Sticco L, Fioriniello S, De Gregorio R, Granata I, Guarracino MR, Maglione V, Johannes L, Bellenchi GC, Hoshino M, Setou M, D'Esposito M, Luini A, D'Angelo G. 2018. Glycosphingolipid metabolic reprogramming drives neural differentiation. The EMBO Journal 37:e97674. doi:10.15252/embj. 201797674

Sanjana NE, Cong L, Zhou Y, Cunniff MM, Feng G, Zhang F. 2012. A transcription activatorlike effector toolbox for genome engineering. Nat Protoc 7:171-192. doi:10.1038/nprot.2011.431

Schaukowitch K, Reese AL, Kim S-K, Kilaru G, Joo J-Y, Kavalali ET, Kim T-K. 2017. An Intrinsic Transcriptional Program Underlying Synaptic Scaling during Activity Suppression. Cell Rep 18:1512-1526. doi:10.1016/j.celrep.2017.01.033

Schindelin J, Arganda-Carreras I, Frise E, Kaynig V, Longair M, Pietzsch T, Preibisch S, Rueden C, Saalfeld S, Schmid B, Tinevez J-Y, White DJ, Hartenstein V, Eliceiri K, Tomancak P, Cardona A. 2012. Fiji: an open-source platform for biological-image analysis. Nat Methods 9:676-682. doi:10.1038/nmeth.2019

Sillar KT. 2009. Mauthner cells. Current Biology 19:R353-R355. doi:10.1016/j.cub.2009.02.025

Sohal VS, Rubenstein JLR. 2019. Excitation-inhibition balance as a framework for investigating mechanisms in neuropsychiatric disorders. Molecular Psychiatry 24:1248-1257. doi:10.1038/541380-019-0426-0 
Sultana R, Yu C-E, Yu J, Munson J, Chen D, Hua W, Estes A, Cortes F, de la Barra F, Yu D, Haider ST, Trask BJ, Green ED, Raskind WH, Disteche CM, Wijsman E, Dawson G, Storm DR, Schellenberg GD, Villacres EC. 2002. Identification of a Novel Gene on Chromosome 7q11.2 Interrupted by a Translocation Breakpoint in a Pair of Autistic Twins. Genomics 80:129-134. doi:10.1006/geno.2002.6810

Sztainberg Y, Zoghbi HY. 2016. Lessons learned from studying syndromic autism spectrum disorders. Nature Neuroscience 19:1408-1417. doi:10.1038/nn.4420

Turrigiano GG, Leslie KR, Desai NS, Rutherford LC, Nelson SB. 1998. Activity-dependent scaling of quantal amplitude in neocortical neurons. Nature 391:892-896. doi:10.1038/36103

Turrigiano GG, Nelson SB. 2004. Homeostatic plasticity in the developing nervous system. Nat Rev Neurosci 5:97-107. doi:10.1038/nrn1327

Wang Q, Geng Z, Gong Y, Warren K, Zheng H, Imamura Y, Gao Z. 2018. WDR68 is essential for the transcriptional activation of the PRC1-AUTS2 complex and neuronal differentiation of mouse embryonic stem cells. Stem Cell Research 33:206-214. doi:10.1016/j.scr.2018.10.023

Watanabe T, Shimazaki T, Mishiro A, Suzuki T, Hirata H, Tanimoto M, Oda Y. 2013. Coexpression of auxiliary Kv $\beta 2$ subunits with $\mathrm{Kv} 1.1$ channels is required for developmental acquisition of unique firing properties of zebrafish Mauthner cells. Journal of Neurophysiology 111:1153-1164. doi:10.1152/jn.00596.2013

Watanabe T, Shimazaki T, Oda Y. 2017. Coordinated Expression of Two Types of LowThreshold K+ Channels Establishes Unique Single Spiking of Mauthner Cells among Segmentally Homologous Neurons in the Zebrafish Hindbrain. eNeuro 4. doi:10.1523/ENEURO.0249-17.2017

Westerfield M. 2000. The Zebrafish Book: A Guide for the Laboratory Use of Zebrafish (Danio Rerio). University of Oregon Press.

Wolman M, Granato M. 2012. Behavioral Genetics in Larval Zebrafish: Learning from the Young. Dev Neurobiol 72:366-372. doi:10.1002/dneu.20872

Wolman MA, Jain RA, Marsden KC, Bell H, Skinner J, Hayer KE, Hogenesch JB, Granato M. 2015. A Genome-wide Screen Identifies PAPP-AA-Mediated IGFR Signaling as a Novel Regulator of Habituation Learning. Neuron 85:1200-1211. doi:10.1016/j.neuron.2015.02.025

Zottoli SJ. 1977. Correlation of the startle reflex and Mauthner cell auditory responses in unrestrained goldfish. J Exp Biol 66:243-254. 
A

bioRxiv preprint doi: https://doi.org/10.1101/2020.11.04.367821; this version posted November 4, 2020. The copyright holder for this preprint

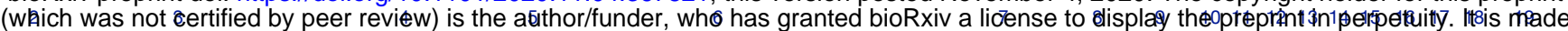

1 (which was not eertified by peer review) is the aethorender, who has granted bioRxiv a li
Left TALEN
KpnI
Right TALEN
$W T$ CATCCAGCTGGGAGTGCCTACTCAGgtaccagtcaccacctaaagtgctattacatggtctct--------------gtta
$W T^{*}$ CATCCAGCTGGGAGTGCCTACTCAGgtaccagtcaccacctaaagtgctattatatggtctctattacatggtctctgtta $\begin{array}{lllllllll}H & P & A & G & S & A & Y & S\end{array}$

ncb101 CATCCAGCTGGGAGTGCCTACTCA-------gtcaccacctaaagtgctattatatggtctctattacatggtctctgtta -7 nt ncb102 CATCCAGCTGGGAGTGCCTACTCAGgt------cacCacctaaagtgctattatatggtctctattacatggtctctgtta -6 nt ncb103 CATCCAGCTGGGAGTGCCTACTC----------------ctaaagtgctattatatggtctctattacatggtctctgtta -16 nt ncb104 CATCCAGCTGGGAGTGCCTACTCA-----------cCacctaaactgctactatagggtctctattacatggtctctgtta -11 nt ncb105 CATCCAGCTGGGAGTGCCTACTCAGg-accagtcaccacctaaagtgctattatatggtctctattacatggtctctgtta -1 nt

B
Auts2awt PR1 $=$ PR2 1 Auts2 family 1278
Auts2ancb104
PR1 I 504
498

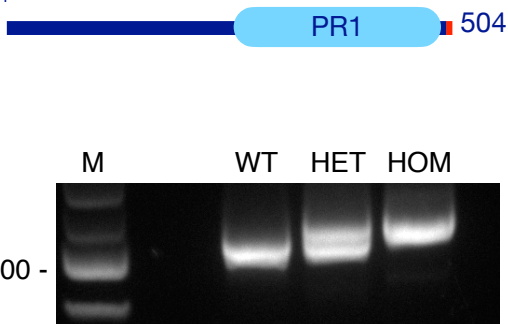
WT HPAGSAYSEQDILRQELN...
ncb101 HPAGSAYSNKTFSGRN*
ncb102 HPAGSAYSEQDILRQELN...
ncb103 HPAGSAYS*
ncb104 HPAGSAYSPPKLLL*
ncb105 HPAGSAYSGPNKTFSGRN *

Figure 1. 
A

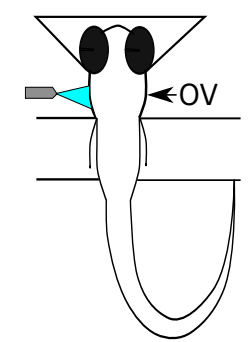

Contralateral tail bend

B

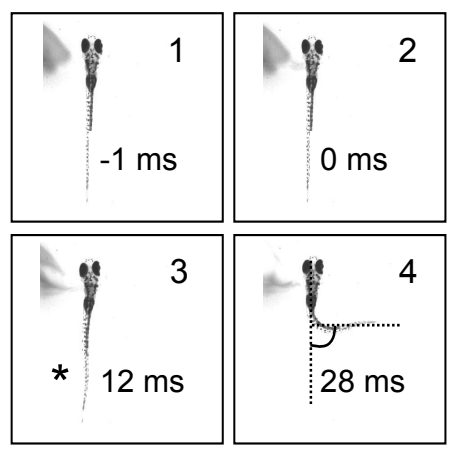

C
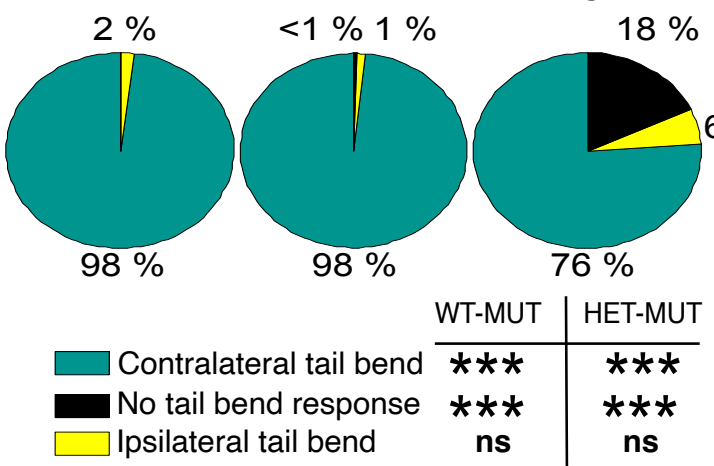

D

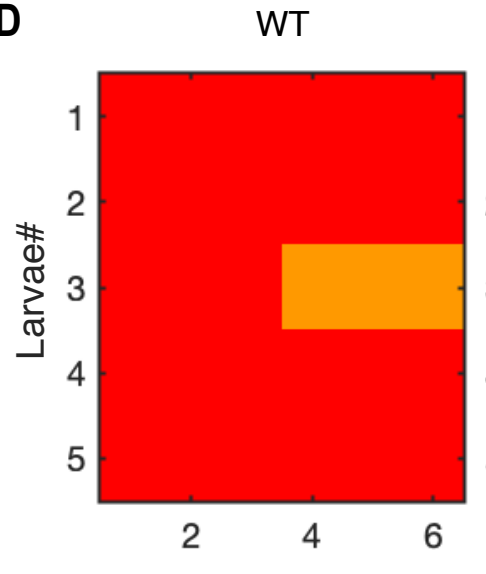

Trial \#

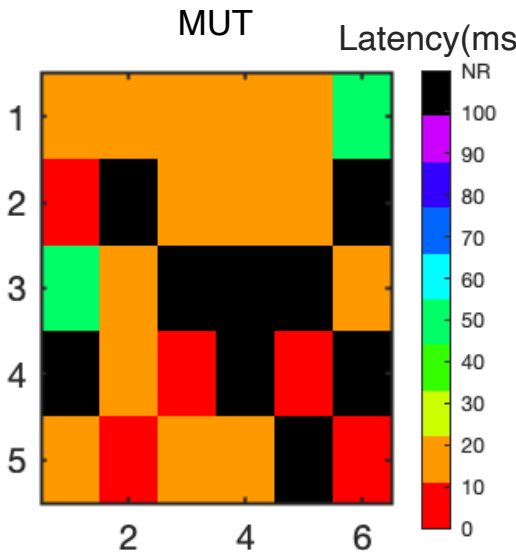

G
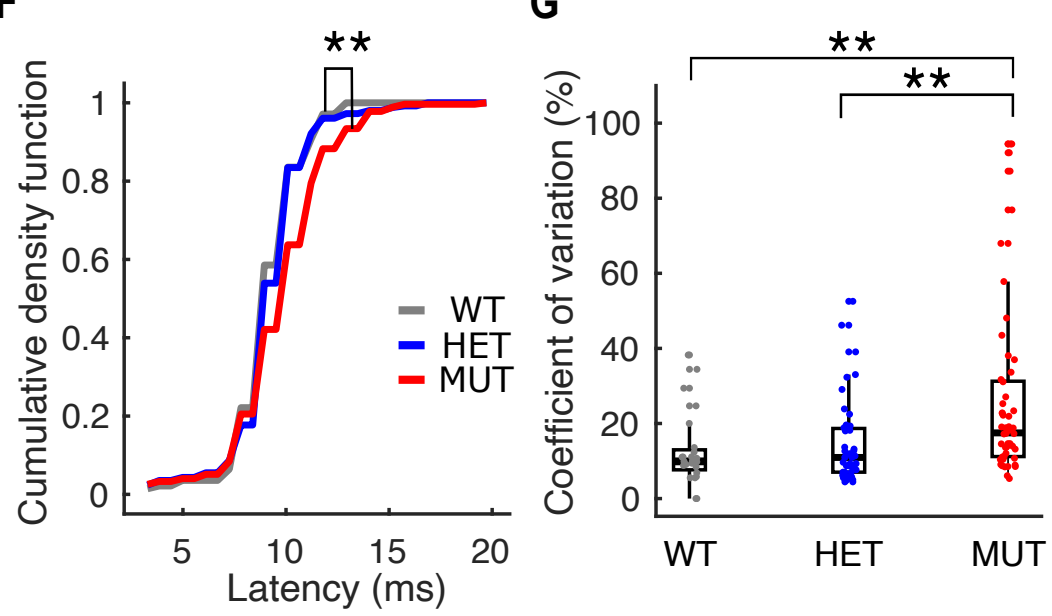

E

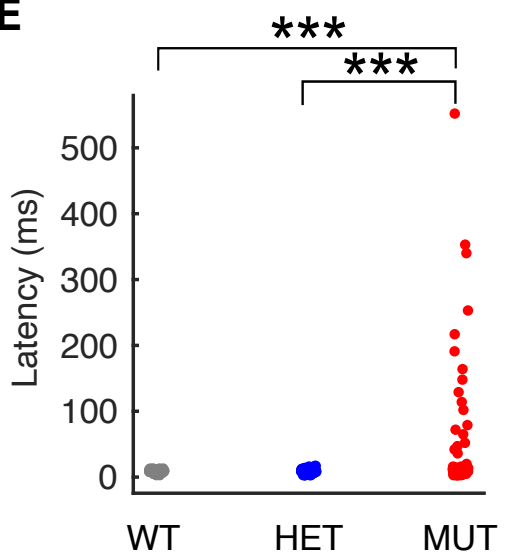

H

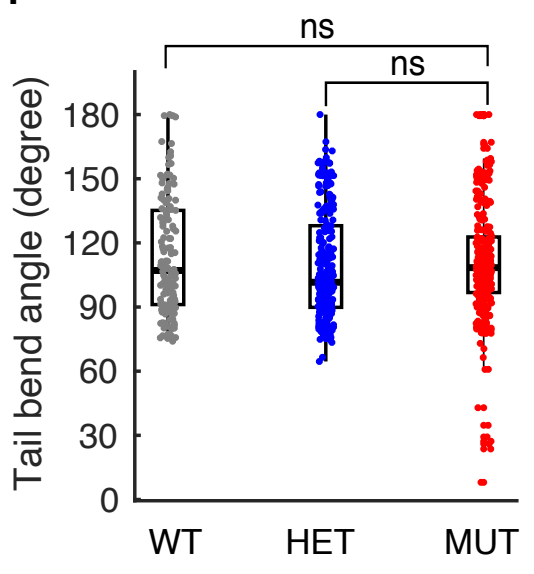

Figure 2. 
A

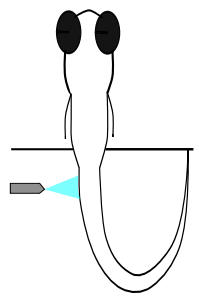

Contralateral tail bend

D

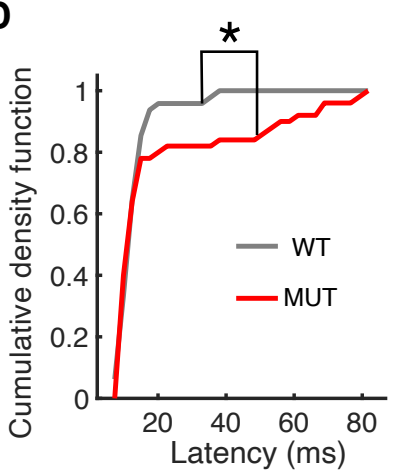

B

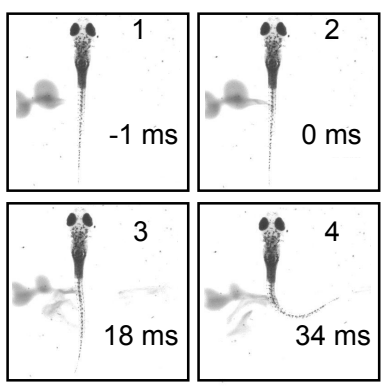

E

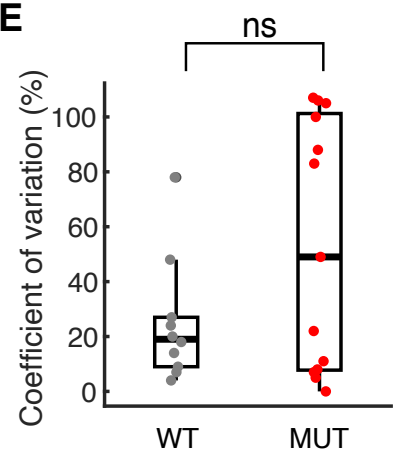

C

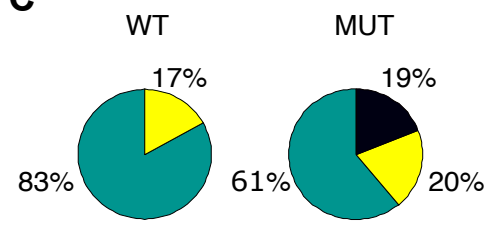

Contralateral tail bend $\quad * *$

No tail bend response $\quad * * *$ Ipsilateral tail bend

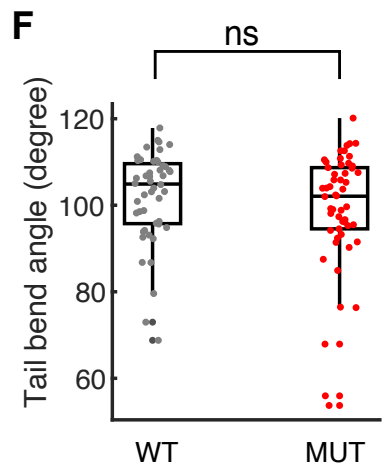

Figure 3. 
A

B
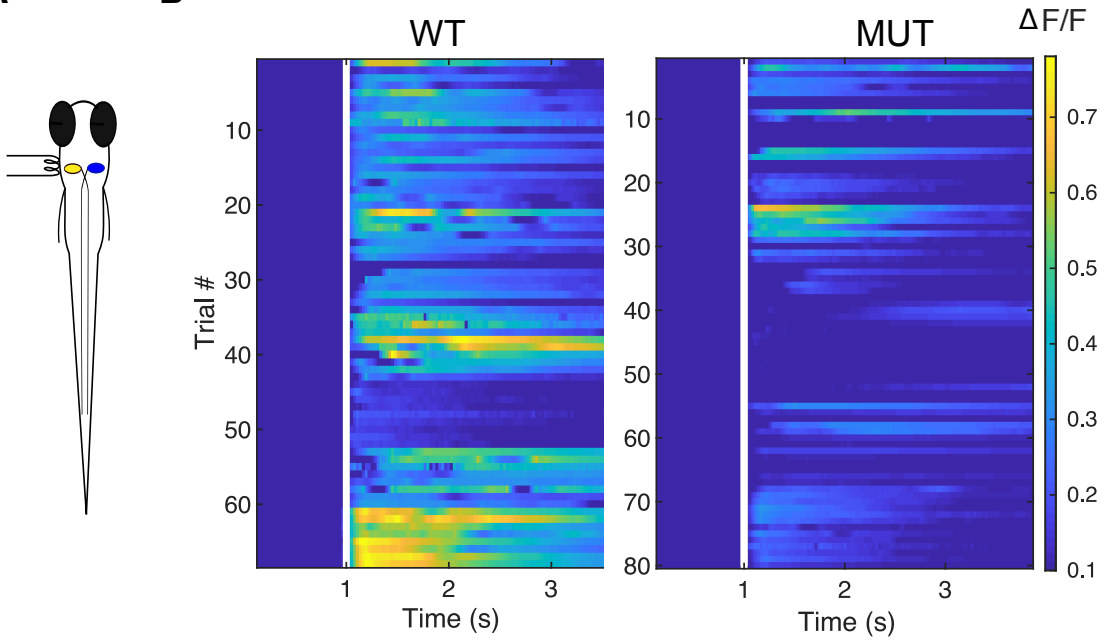

C
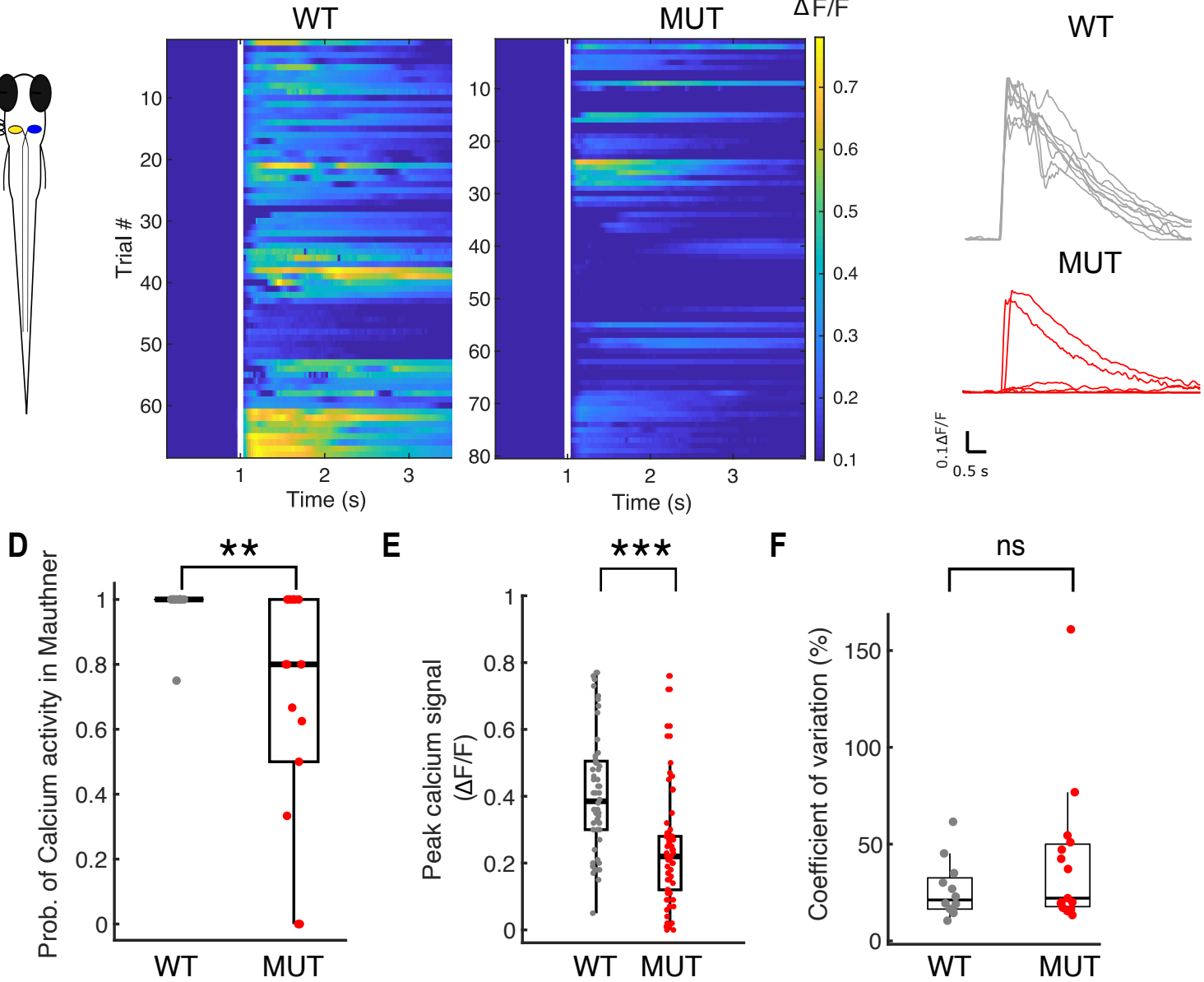

E

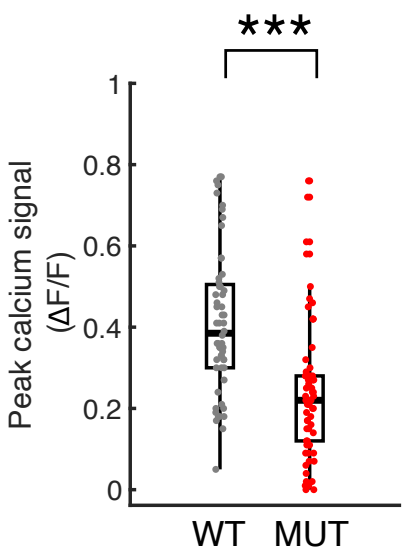

F
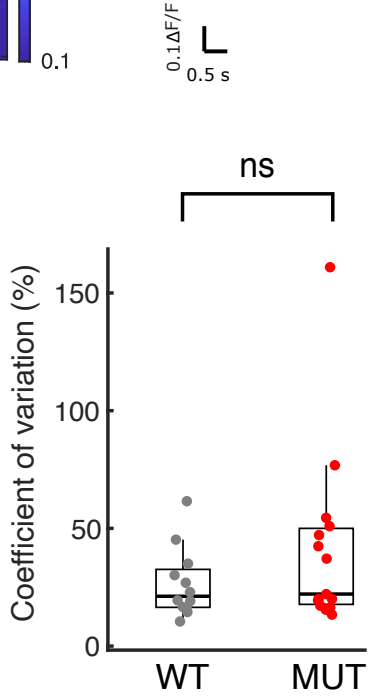

Figure 4. 
A

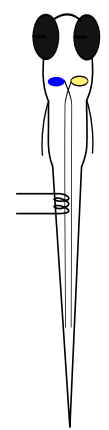

B

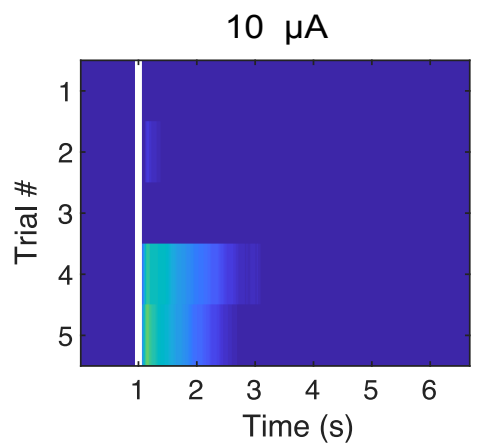

Antidromic stimulation

C

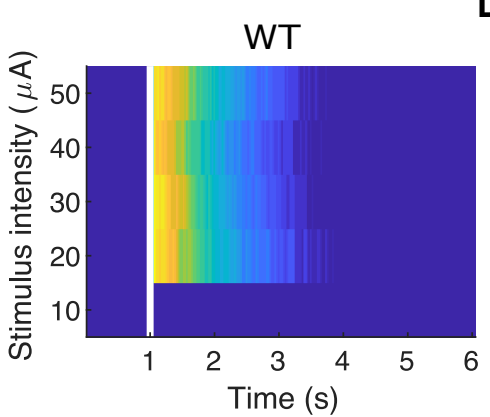

$\mathbf{F}$

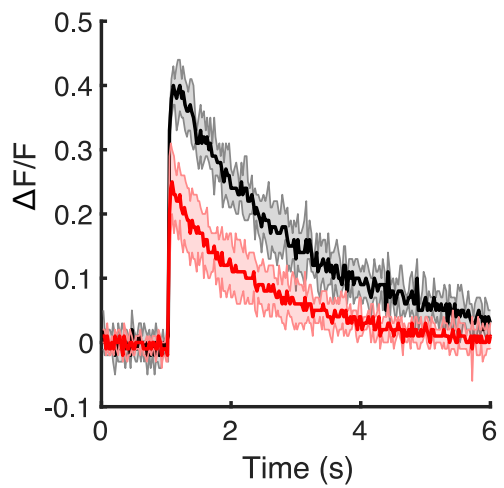

G

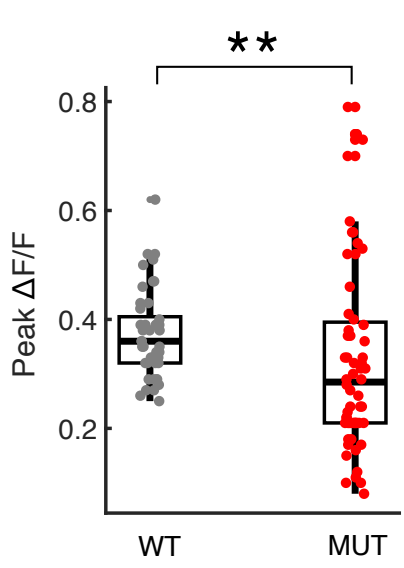

D

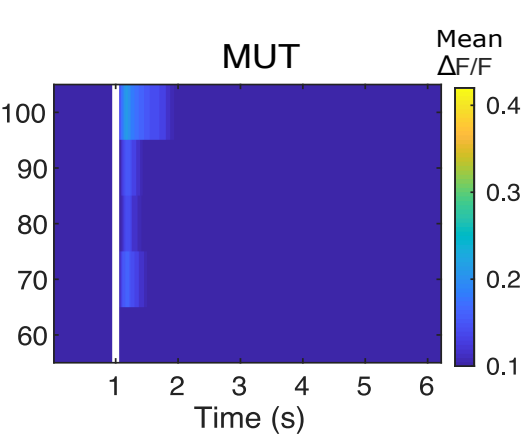

E

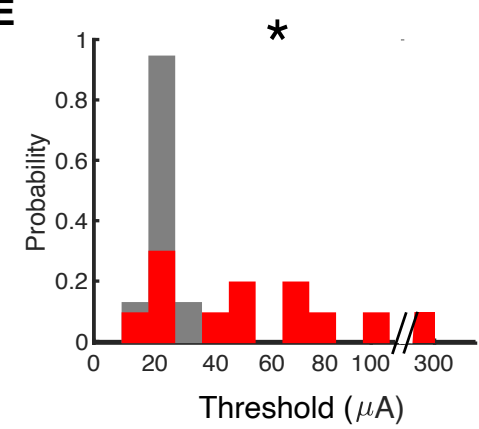

H

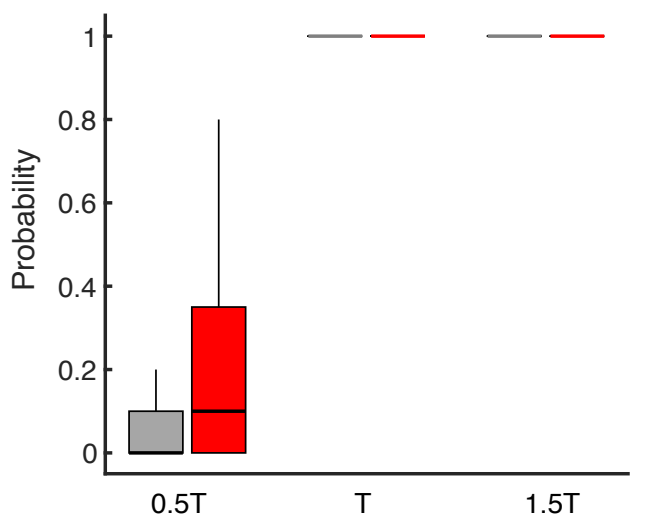

Figure 5. 
